\title{
Biofeedback: An Effective Add-on Treatment for Migraine Headache Alongside Medication Therapy
}

\author{
Mohammad Reza Hossein Tehrani ${ }^{1}$ (D), Abolfazl Ghoreishi ${ }^{2}$ (D), Leila Kalhor ${ }^{3}$ (D), \\ Alireza Khosravi4,5 (D), Aboreza Ghoreishi 6*(iD)
}

1. Neurology Research Center, School of Medicine, Shiraz University of Medical Sciences, Shiraz, Iran

2. Dept. of Psychiatry, Shahid Beheshti-Hospital, School of Medicine, Zanjan University of Medical Sciences, Zanjan, Iran

3. Nuclear Medicine Research Center, School of Medicine, Shiraz University of Medical Sciences, Shiraz, Iran

4. Clinical Immunology Research Center, Zahedan University of Medical Sciences, Zahedan, Iran

5. Dept. of Neurology, School of Medicine, Zahedan University of Medical Sciences, Zahedan, Iran

6. Stroke Research Group, Dept. of Neurology, Vali-e-Asr-Hospital, School of Medicine, Zanjan University of Medical Sciences, Zanjan, Iran

\begin{tabular}{c}
\hline Article Info \\
\hline doi 10.30699/jambs.29.132.1 \\
\hline Received: 2020/06/16; \\
Accepted: 2020/07/16; \\
Published Online: 11 Nov 2020 \\
\hline Use your device to scan and read the \\
article online \\
a․ \\
\hline
\end{tabular}

Corresponding Information: AbdolReza Ghoreishi,

Dept. of Neurology, Vali-e-AsrHospital, School of Medicine, Zanjan University of Medical Sciences, Zanjan, Iran

E-Mail:

ar.ghoreishy@gmail.com

\begin{abstract}
Background \& Objective: Migraine is an occasional headache that represents neurological and gastrointestinal symptoms, as well as changes in the autonomic nervous system. Biofeedback is a non-pharmacological technique used to treat migraine headaches and is proven to reduce headaches and improve performance. The present study aimed to compare the efficacy of biofeedback and pharmacological treatments to find the best treatment strategy for migraine headaches.
\end{abstract}

Materials \& Methods: This randomized clinical trial was performed on 86 patients who referred to Noor Psychiatric Clinic and Neurology Clinic of Valiasr Hospital, Zanjan, Iran. Patients were divided into two groups of daily treatment with medication and treatment with medicine and biofeedback. Cases were monitored every two months using interviews and questionnaires.

Results: The study was carried out on 86 migraine patients with the age range of 3145 years for 3 months. Most of the patients were female, including $90.7 \%$ of the individuals in the case group and $81.4 \%$ of the control group. The frequency distribution of medication use was not different between the two groups $(P=0.744)$. Most of the participants had a history of more than 1 year of headache. During the treatment, the frequency and severity of attacks reduced obviously until the $8^{\text {th }}$ week. The decrease in the Migraine Disability Assessment (MIDAS) score was more significant in the biofeedback group, except in the $10^{\text {th }}$ and $12^{\text {th }}$ weeks. However, the decline in the MIDAS score was not significant. Moreover, the reduction in the frequency of attacks remained significant until the end of the study.

Conclusion: It can be concluded that the combination of biofeedback treatment and medication therapy provides a more rapid response than pharmacological treatment alone. Therefore, biofeedback is an effective add-on therapy, which can be taken into consideration for diminishing all aspects of migraine headache attacks.

Keywords: Biofeedback, Effective, Migraine headache, Pharmacological, Treatment

\section{Introduction}

One of the most common headache types is the migraine headache (1). According to the International Classification of Headache Disorders (2), chronic migraine is a type of headache that occurs 15 or more days per month. The prevalence of migraine in Europe is $15 \%$ with a range of $12 \%-27.5 \%$ depending on the country (1). Migraine is a neurological condition characterized by unilateral headache, light and sound intolerance, vomit, and nausea. Patients who suffer from migraine headaches experience functional impairment at work, school, and home. To reduce pain, biofeedback therapy emphasizes the role of patients in managing these conditions and improving the consequences of pain (3).

Biofeedback is a behavioral medical technique that has been proven to reduce headaches and enhance performance. It is a non-pharmacological technique for headache prevention and control. The efficacy of 
biofeedback has been demonstrated in over 100 investigations during 25 years of research. It is an influential method for reducing the severity and frequency of headaches and helps patients to decrease their use of medication. Biofeedback therapy is effective for pain management and is associated with a decline in depression among adolescents who have a migraine headache, chronic headache, or chronic abdominal pain (4).

The results of a study indicated that more than $90 \%$ of individuals in the United States of America had experienced headaches, $50 \%$ had suffered from one of the headache types, and $25 \%$ had a recurrent disabling headache (5). The prevalence of migraine is higher among females than males and in some studies, 65-95\% of the participants had a positive family history $(6,7)$. The World Health Organization (WHO) considers migraine headaches as one of the 20 disabling disorders around the world with a functional impairment rate of $11.2 \%$ to $30 \%$ in some studies $(8-10)$.

Consequently, the present study aimed to compare the efficacy of biofeedback and pharmacological treatments in the treatment of migraine headaches among Iranians, especially the residents of Zanjan city because of the probable difference in response to non-pharmacological treatments.

\section{Materials and Methods}

\section{Study Design}

This randomized clinical trial was approved and monitored by Zanjan University of Medical Sciences and Ethics Committee with the code of 91/12-170-04. Written consent forms were taken from the patients for initiating biofeedback therapy and complete information was provided about their treatment feedback.

In the present study, biofeedback treatment was evaluated and compared with pharmacologic therapy. In the beginning, 94 participants who met the inclusion criteria entered the study. Four patients stopped taking medications and one person experienced the adverse effects of medicines and stopped using. One case became pregnant, two patients left the study because of neck pain, and finally, 86 participants finished the study.

Patients in this investigation referred to Noor Psychiatric Clinic and Neurology Clinic of Valiasr Hospital, Zanjan, Iran. They were divided into two groups, one of which was received Gelofen (PRN) or a similar analgesic, Inderal $20 \mathrm{mg}$ (TDS), and Nortriptyline $25 \mathrm{mg}$ daily as the standard pharmacological treatment, and the other group received biofeedback and pharmacological treatment.

Biofeedback therapy was performed in 10 sessions for 15 min according to the corresponding protocol (i.e., BPP). The duration of biofeedback therapy was five weeks as two sessions per week and the duration of active prophylaxis treatment with medications was one month during the follow-up. In order to relieve severe headache attacks that occurred more than once a week, the follow-up was continued. Patients were monitored every two months based on interviews and questionnaires to reduce the number of attacks, the severity of attacks, and the need for PRN treatment.

\section{Inclusion and Exclusion Criteria}

The inclusion criteria entailed not having received specific migraine treatment in the previous month and probably patients who had a migraine headache for the first time or received treatment which had been discontinued for any reason during the last 5 days. The criteria for selecting patients were based on the computerized randomization tables in the Excel software (Microsoft office 2003). The exclusion criteria were being migraine-resistant, being rural without access to the clinic during follow-up, and not cooperating completely.

\section{Data Collection}

The biofeedback session was conducted by experts. Students interviewed the patients and filled out the questionnaires concerning the severity and frequency of migraine attacks. The follow-up consisted of these three measures: 1) the number of attacks, 2) severity of attacks, and 3) loss of function as measured by the Migraine Disability Assessment (MIDAS) questionnaire. Finally, the data from the completed questionnaires related to eight follow-up sessions per patient were categorized and analyzed.

\section{Statistical Analysis}

Descriptive statistics showed changes in the mean of the four outcome variables. Data analysis was performed by the Chi-square test, Friedman test for repeated measures, Mann-Whitney U test, and independent t-test using the SPSS 16 (SPSS Inc., Chicago, Ill., USA). Pvalue $<0.05$ was considered significant.

\section{Results}

In the present study, the combination of biofeedback treatment and medications was evaluated and compared with pharmacologic therapy alone. The current investigation was performed on 86 patients suffering from migraine. The effect of biofeedback and medication treatment was evaluated on 3 outcome variables, including the number of attacks, the severity of attacks, and the performance loss score obtained by the MIDAS questionnaire.

The frequency distribution of headache stimuli revealed no significant difference between the two groups $(P=0.15)$. Both groups were found to have more than one stimulus for their headache with $53.5 \%$ for the case group and $37.2 \%$ for the control group. A comparison of the frequency distribution of migraine symptoms showed no significant difference between the two groups $(P=0.058)$. This frequency demonstrated that $65.1 \%$ of the patients in the case group and $44.2 \%$ of the individuals in the control group had more than one symptom for their headache. The frequency of medication use was $62.8 \%$ and $58.1 \%$ in 
the case and control groups, respectively. The latter factor did not have a statistically significant difference between the two groups $(P=0.744)$.

The two groups were not significantly different in terms of age, gender, and occupation. Most of the patients in both groups were $31-45$ years old and most of the patients were female $(90.7 \%$ of the case group and $81.4 \%$ of the control group). Table 1 shows the demographic characteristics and general measures of participants in both case and control groups. We found that the smoking rate was significantly different between the two groups $(P=0.028)$. Moreover, a significant difference was observed between the groups regarding not taking painkillers, which was $25 \%$ in the case group and $4.71 \%$ in the control group $(P=0.007)$.

Table 1. Demographic and general measures of patients

\begin{tabular}{|c|c|c|c|}
\hline Variables & $\begin{array}{c}\text { Case group } \\
\text { No }(\%)\end{array}$ & $\begin{array}{c}\text { Control group } \\
\text { No }(\%)\end{array}$ & P-value \\
\hline \multicolumn{3}{|l|}{ Age } & \multirow{4}{*}{0.158} \\
\hline $15-30$ & $13(32)$ & $16(37.2)$ & \\
\hline $31-45$ & $26(60.5)$ & 18(41.9) & \\
\hline$\geq 46$ & $4(9.3)$ & $9(20.9)$ & \\
\hline \multicolumn{3}{|l|}{ Sex } & \multirow{3}{*}{0.176} \\
\hline Female & $39(90.7)$ & $35(81.4)$ & \\
\hline male & $4(9.3)$ & $8(18.6)$ & \\
\hline \multicolumn{3}{|l|}{ Job } & \multirow{3}{*}{0.500} \\
\hline Housekeeper & $35(81.4)$ & $34(79.1)$ & \\
\hline others & $8(18.6)$ & $9(20.9)$ & \\
\hline \multicolumn{3}{|l|}{ Smoking } & \multirow{3}{*}{0.028} \\
\hline No & $43(100)$ & $38(88.4)$ & \\
\hline Yes & 0 & $5(11.6)$ & \\
\hline \multicolumn{3}{|l|}{ Positive history of Psychiatric } & \multirow{3}{*}{0.295} \\
\hline No & $36(83.7)$ & $33(76.7)$ & \\
\hline Yes & $7(16.3)$ & $10(23.3)$ & \\
\hline \multicolumn{3}{|c|}{ Positive family history of headache } & \multirow{3}{*}{0.500} \\
\hline No & $25(58.1)$ & $26(60.5)$ & \\
\hline Yes & $18(41.9)$ & $17(39.5)$ & \\
\hline
\end{tabular}

Table 2 demonstrates the mean of migraine treatment in the case group. All the variables decreased significantly during migraine therapy. In Table 3, the treatment was evaluated based on each variable in the control group. All three variables, namely the number of attacks, headache severity, and MIDAS score diminished and the difference was statistically significant. Table 4 indicates the mean MIDAS scores of the two groups. There was no significant difference at the baseline $(P=0.766)$, in the $10^{\text {th }}$ week $(P=0.298)$, and in the $12^{\text {th }}$ week $(P=0.057)$.

Table 2. The comparison of migraine therapy based on mean in case group

\begin{tabular}{|c|c|c|c|c|c|c|c|c|c|}
\hline \multirow{2}{*}{ Variables } & $\begin{array}{l}\text { Beginning of } \\
\text { study }\end{array}$ & $\begin{array}{l}\text { Week } \\
\text { one }\end{array}$ & $\begin{array}{l}\text { Week } \\
\text { Two }\end{array}$ & $\begin{array}{l}\text { Week } \\
\text { Four }\end{array}$ & $\begin{array}{l}\text { Week } \\
\text { Six }\end{array}$ & $\begin{array}{l}\text { Week } \\
\text { Eight }\end{array}$ & $\begin{array}{c}\text { Week } \\
\text { Ten }\end{array}$ & $\begin{array}{c}\text { Week } \\
\text { Twelve }\end{array}$ & \multirow{2}{*}{ P-value } \\
\hline & Mean (SD) & $\begin{array}{c}\text { Mean } \\
\text { (SD) }\end{array}$ & $\begin{array}{c}\text { Mean } \\
(\text { SD) }\end{array}$ & $\begin{array}{c}\text { Mean } \\
\text { (SD) }\end{array}$ & $\begin{array}{c}\text { Mean } \\
\text { (SD) }\end{array}$ & $\begin{array}{c}\text { Mean } \\
\text { (SD) }\end{array}$ & $\begin{array}{c}\text { Mean } \\
(\mathrm{SD})\end{array}$ & $\begin{array}{c}\text { Mean } \\
\text { (SD) }\end{array}$ & \\
\hline $\begin{array}{c}\text { No. of } \\
\text { Migraine } \\
\text { Attacks }\end{array}$ & $3.84(1.66)$ & $\begin{array}{c}1.51 \\
(1.31)\end{array}$ & $\begin{array}{c}1.24 \\
(1.07)\end{array}$ & $\begin{array}{c}1.64 \\
(1.02)\end{array}$ & $\begin{array}{c}1.55 \\
(1.14)\end{array}$ & $\begin{array}{c}1.77 \\
(1.53)\end{array}$ & $\begin{array}{c}1.80 \\
(1.42)\end{array}$ & $\begin{array}{c}1.46 \\
(1.16)\end{array}$ & $<0.0001$ \\
\hline $\begin{array}{l}\text { Severity of } \\
\text { Migraine } \\
\text { attacks }\end{array}$ & $8.21(1.80)$ & $\begin{array}{c}3.42 \\
(2.71)\end{array}$ & $\begin{array}{c}2.48 \\
(2.40)\end{array}$ & $\begin{array}{c}3.34 \\
(2.53)\end{array}$ & $\begin{array}{c}3.39 \\
(2.51)\end{array}$ & $\begin{array}{c}3.34 \\
(3.28)\end{array}$ & $\begin{array}{c}3.65 \\
(3.56)\end{array}$ & $\begin{array}{c}3.52 \\
(3.35)\end{array}$ & $<0.0001$ \\
\hline MIDAS Score & $15.88(12.47)$ & $\begin{array}{c}1.00 \\
(0.58)\end{array}$ & $\begin{array}{c}0.67 \\
(0.30)\end{array}$ & $\begin{array}{c}1.20 \\
(0.49)\end{array}$ & $\begin{array}{l}1.15 \\
(0.6)\end{array}$ & $\begin{array}{c}1.45 \\
(0.93)\end{array}$ & $\begin{array}{c}1.59 \\
(1.19)\end{array}$ & $\begin{array}{c}1.04 \\
(0.63)\end{array}$ & $<0.0001$ \\
\hline
\end{tabular}


Table 3. Comparison of migraine therapy based on means in control group.

\begin{tabular}{|c|c|c|c|c|c|c|c|c|c|}
\hline \multirow{2}{*}{ Variables } & $\begin{array}{l}\text { Beginning } \\
\text { of study }\end{array}$ & $\begin{array}{l}\text { Week } \\
\text { one }\end{array}$ & $\begin{array}{l}\text { Week } \\
\text { Two }\end{array}$ & $\begin{array}{l}\text { Week } \\
\text { Four }\end{array}$ & $\begin{array}{l}\text { Week } \\
\text { Six }\end{array}$ & $\begin{array}{l}\text { Week } \\
\text { Eight }\end{array}$ & $\begin{array}{c}\text { Week } \\
\text { Ten }\end{array}$ & $\begin{array}{c}\text { Week } \\
\text { Twelve }\end{array}$ & \multirow{2}{*}{ P-value } \\
\hline & $\begin{array}{c}\text { Mean } \\
\text { (SD) }\end{array}$ & $\begin{array}{c}\text { Mean } \\
\text { (SD) }\end{array}$ & $\begin{array}{c}\text { Mean } \\
\text { (SD) }\end{array}$ & $\begin{array}{c}\text { Mean } \\
\text { (SD) }\end{array}$ & $\begin{array}{c}\text { Mean } \\
\text { (SD) }\end{array}$ & $\begin{array}{c}\text { Mean } \\
\text { (SD) }\end{array}$ & $\begin{array}{c}\text { Mean } \\
\text { (SD) }\end{array}$ & $\begin{array}{l}\text { Mean } \\
\text { (SD) }\end{array}$ & \\
\hline $\begin{array}{l}\text { No. of } \\
\text { Migraine } \\
\text { Attacks }\end{array}$ & $\begin{array}{c}3.58 \\
(1.41)\end{array}$ & $\begin{array}{c}2.72 \\
(1.91)\end{array}$ & $\begin{array}{c}2.65 \\
(2.04)\end{array}$ & $\begin{array}{c}2.91 \\
(2.25)\end{array}$ & $\begin{array}{c}2.65 \\
(2.25)\end{array}$ & $\begin{array}{c}2.44 \\
(2.18)\end{array}$ & $\begin{array}{c}2.23 \\
(2.09)\end{array}$ & $\begin{array}{c}2.06 \\
(1.93)\end{array}$ & 0.002 \\
\hline $\begin{array}{c}\text { Severity of } \\
\text { Migraine } \\
\text { attacks }\end{array}$ & $\begin{array}{c}8.51 \\
(1.98)\end{array}$ & $\begin{array}{c}5.19 \\
(2.90)\end{array}$ & $\begin{array}{c}4.47 \\
(2.90)\end{array}$ & $\begin{array}{c}4.91 \\
(3.03)\end{array}$ & $\begin{array}{c}4.53 \\
(3.22)\end{array}$ & $\begin{array}{c}4.65 \\
(2.94)\end{array}$ & $\begin{array}{c}4.42 \\
(2.97)\end{array}$ & $\begin{array}{c}3.91 \\
(2.66)\end{array}$ & $<0.0001$ \\
\hline MIDAS Score & $\begin{array}{c}16.64 \\
(10.94)\end{array}$ & $\begin{array}{c}2.43 \\
(2.28)\end{array}$ & $\begin{array}{c}2.35 \\
(2.26)\end{array}$ & $\begin{array}{c}2.48 \\
(2.26)\end{array}$ & $\begin{array}{c}2.29 \\
(1.93)\end{array}$ & $\begin{array}{c}2.10 \\
(1.79)\end{array}$ & $\begin{array}{c}1.91 \\
(1.60)\end{array}$ & $\begin{array}{c}1.58 \\
(1.21)\end{array}$ & $<0.0001$ \\
\hline
\end{tabular}

Table 4. The comparison of MIDAS score mean in case and control groups.

\begin{tabular}{|cccc}
\hline Variables & Case group & Control group & P-value \\
\hline Study beginning & Mean (SD) & Mean (SD) & 0.766 \\
\hline Week 1 & $15.88(12.47)$ & $16.64(10.95)$ & $<0.0001$ \\
\hline Week 2 & $0.58(1.00)$ & $2.47(2.27)$ & $<0.0001$ \\
\hline Week 4 & $0.30(0.67)$ & $2.26(2.33)$ & $<0.0001$ \\
\hline Week 6 & $0.49(1.20)$ & $2.42(2.27)$ & 0.001 \\
\hline Week 8 & $0.60(0.15)$ & $1.93(2.27)$ & 0.018 \\
\hline Week 10 & $0.93(1.45)$ & $1.91(2.22)$ & 0.298 \\
\hline Week 12 & $1.19(1.59)$ & $1.58(1.89)$ & 0.057 \\
\hline
\end{tabular}

Figures 1 and $\underline{2}$ show the results of evaluating the responses to treatment in both groups during the treatment period. In both groups, the attack severity, the number of attacks, the MIDAS score, and the number of medications decreased during this period and the differences between the two groups were statistically significant.

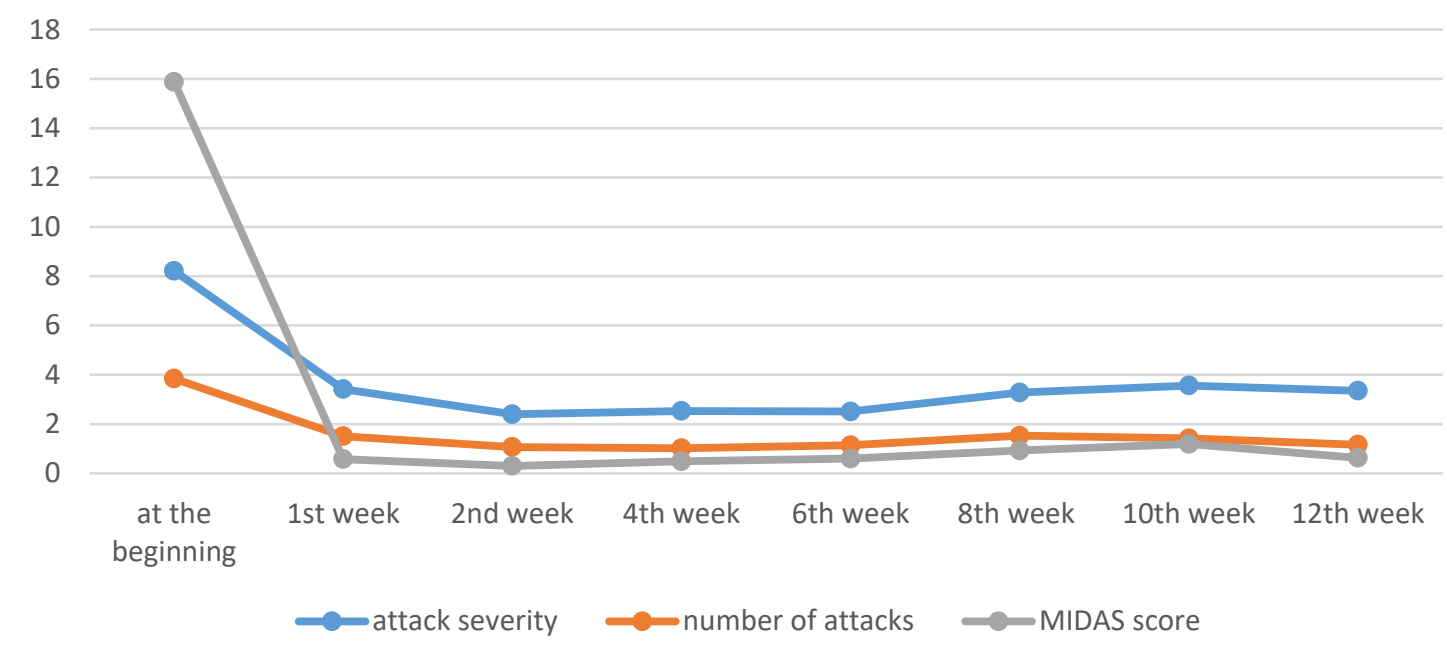

Figure 1. Evaluation of responses to treatments during follow up in control group 


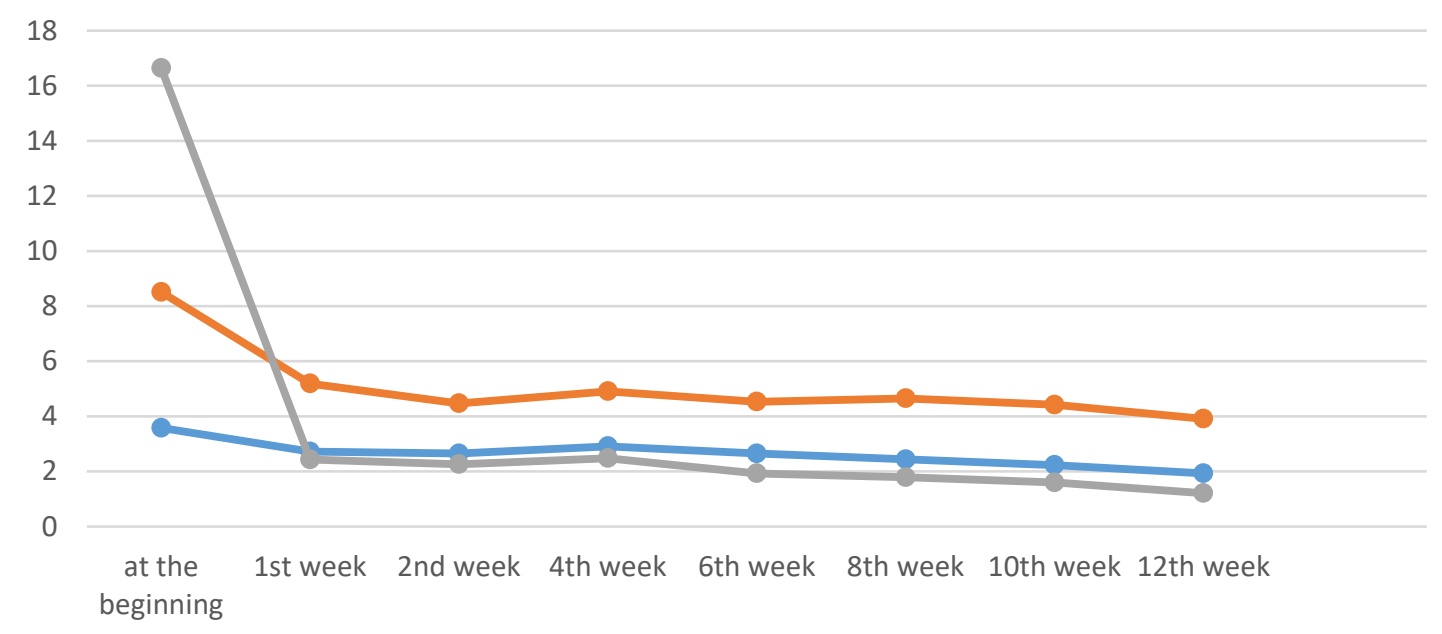

-attack severity $\quad$ number of attacks $\quad$ MIDAS score

Figure 2. Evaluation of responses to treatments during follow up in case group

\section{Discussion}

Migraine is a headache that peaks in the 40s (11) and is more common in women than men (10). The WHO has considered migraine as one of the 20 debilitating diseases in the world (7). Therefore, the diagnosis and treatment of migraine can prevent economic and social costs for society and individuals. Many therapeutic approaches, including pharmacological and nonpharmacological therapies, have been proven to be effective for migraine. Although many studies have been performed on the efficacy of these treatments, few have directly compared the routine treatment protocols for migraine treatment with biofeedback as a nonpharmacological treatment.

Approximately $38 \%$ of the patients with migraine headaches benefit from biofeedback therapy and less than $13 \%$ take medication. Biofeedback therapy reduces migraine severity, frequency, and the distress of the related headaches. Furthermore, it may prevent chronic migraine and improve the quality of life (12).

Patients with similar headaches and demographic characteristics were enrolled in the current study. All the patients experienced at least two attacks per week and none of them were resistant to treatment. The time of the onset of migraine headache varied from the last two months to several years. The mean age was similar between the case and control groups. Most of the patients in the study were female and the prevalence of migraine among women was higher than men in the Iranian population $(90.7 \%$ of the case group and. $81.4 \%$ of the control group).

In the study by Shahraki et al., $60 \%$ of the patients were female. In the latter investigation, the sample size was 1534 cases. Therefore, the prevalence of headache among women was less than that of the present study. Most of the cases in our investigation were

Volume 29, January \& February 2021 housewives, while the participants of the mentioned study were teachers (13).

Although the smoking rate was significantly higher in the control group, this difference is not likely to have a confounding effect because smoking has not been mentioned as a trigger of migraine attacks. The number of pain medications was significantly higher in the case group and it had no confounding effect. The case and control groups were matched based on their history of mental illness and the prevalence of these diseases was about $20 \%$ in both groups. The prevalence of the family history of headache was high in the present study. However, it was not significantly different between the two groups. This result was similar to the findings of Hashemilar et al. (14), who reported the prevalence of $45.6 \%$ for this variable.

The decreasing headache-related performance was measured by the MIDAS questionnaire. This method of measuring performance has been used in other studies, including the study by Mirzaee et al. (7). In the present study, the rate of moderate to severe functional loss was $58.9 \%$ and was similar between the two groups $(51.2 \%$ in the case group and $55.8 \%$ in the control group). This difference was not significant and the severity of performance loss in the two groups was the same as the baseline.

Patients underwent one month of acute treatment (in the biofeedback group) and two months of maintenance treatment (in the medication group) and were followed up during this period. In each follow-up, the differences between the two groups were compared. By the end of the $8^{\text {th }}$ week, all the measured variables had a greater reduction in the biofeedback group. This indicates that the method was more effective than pharmacologic treatment alone. Moreover, it was shown that biofeedback was more 
influential by the $8^{\text {th }}$ week and medication therapy reached this level by the $10^{\text {th }}$ week.

In a meta-analysis by Gosline et al. (15), 18 clinical trials were evaluated and it was indicated that the nonpharmacological treatments, such as biofeedback were more effective in all studies. In another research (16), the therapeutic impact of biofeedback was investigated in 37 patients suffering from migraine. It was observed that the frequency of attacks decreased and this effect was sustained during the follow-up period.

Another study (17) showed that biofeedback treatment significantly reduced the frequency of migraine attacks and pain. These authors suggested further researches with more patients and a placebo group to prove the efficacy of this method. Another study (18) demonstrated that biofeedback therapy had good feasibility and could be implemented effectively in the care system.

\section{Conclusion}

It can be concluded that the rate of response to the combination of biofeedback treatment and medical therapy is higher and satisfactory results could be achieved more rapidly than medication therapy alone. This feature can be useful in many patients, whose quality of life has declined due to headaches and they can return to normal living conditions. The results of this study showed that biofeedback along with pharmacologic treatment can be very helpful in treating patients with migraine headaches. The greatest advantages of biofeedback treatment were faster cure than medical treatment and fewer side effects noted for this approach. Consequently, this practice can be useful at the beginning of the treatment protocol for enhancing efficacy.

\section{Limitations}

The limitation of the current study was the short duration of the follow-up period. As a result, even a few headache attacks could reduce the difference between the two groups. Further studies with longer durations are recommended for making better evaluations.

\section{Acknowledgments}

The authors thank all those who helped them writing this article.

\section{Ethical considerations}

Ethical issues (Including plagiarism, informed consent, misconduct, data fabrication and/or falsification, double publication and/or submission, redundancy, etc.) have been completely observed by the authors.

\section{Funding and support}

This research resulted from an independent research without receiving any financial support.

\section{Conflict of Interest}

Authors declared no conflict of interest.

\section{References}

1. Stovner LJ, Zwart JA, Hagen K, Terwindt GM, Pascual J. Epidemiology of headache in Europe. Eur J Neurol. 2006;13(4):333-45.

2. Olesen J, Bes A, Kunkel R, et al. The international classification of headache disorders, (beta version). Cephalalgia. 2013;33(9):629-808. [DOI:10.1111/j.1468-1331.2006.01184.x]

3. de Tommaso M, Delussi M. Nociceptive blink reflex habituation biofeedback in migraine. Funct Neurol. 2017;32(3):123-30. [DOI:10.11138/FNeur/2017.32.3.123]

4. Rotkis LN, Abelon R, Breuner CC. The effect of biofeedback therapy on depression and anxiety in the pediatric and adolescent when used to treat migraines, chronic headaches and chronic abdominal pain. J Adolescent Health. 2014;54(2):S42. [DOI:10.1016/j.jadohealth.2013.10.097]

5. Ballantyne JC, Fishman SM, Borsook D, Abdi S, LeBel A, McPeek B. The massachusetts general hospital handbook of pain management: Lippincott Williams and Wilkins; 2001.

6. Mirzayee Gh. Kheiri S, khosravi Sh, Jeevad N. Comparison of relieving effect of intravenous dexamethasone with and without superficial temporal artery compression in acute migraine attack. J Shahre -Kord Med Univ Sci. 2011;18(13):3-24. [in Persian]

7. Mirzayee Gh. Evaluation of common migraine prevalence and functional decrement in high school girls in Shahre-Kord in 1381. J ShahreKord Med Univ Sci. 2003;5(4):55-62. [in Persian]

8. Lawrence EC. Diagnosis and Management of Migraine Headaches. Southern Med J. 2004;97:11. [DOI:10.1097/01.SMJ.0000144634.76817.8F]

9. Durham CF, Alden KR, Dalton JA, et al. Quality of life and productivity in nurses reporting migraine. Headache. 1998;38(6):427-35. [DOI:10.1046/i.1526-4610.1998.3806427.x]

10. Henry P, Auray JP, Gaudin AF, et al. Prevalence and clinical characteristics of migraine in France. Neurology. 2002;59(2):232-7. [DOI:10.1212/WNL.59.2.232] 
11. Loretta L, Mueller D. Diagnosing and managing migraine headache. J Am Osteopath Assoc. 2007;107(10 suppl 6).

12. Ha H, Gonzalez A. Migraine Headache Prophylaxis. Am Fam Physician. 2019;99(1):1724.

13. Shahraki M, Heydari S, Moghtaderi A, Mirshekari H. Prevalence of migraine in Zahedan School Teachers. Zahedan Med School J. 2011(2):20-25. [in Persian]

14. Hashemilar M, Amini-sani N, Savadi-Oskouee D, Yousefian M. Prevalence of migraine among Ardabil university of medical sciences students. J Ardabil Univ Med Sci, 2004;11(3):64-69 [in Persian]

15. Goslin RE, Gray RN, McCrory DC, Penzien D, Rains J, Hasselblad V. Behavioral and Physical Treatments for Migraine Headache. Rockville (MD): Agency for Health Care Policy and Research (US); 1999.

16. Khani H, Abedini M, Zarvani A, Azadmarzabadi A, Montazeri A, Roshanbakhsh R. The effect of topiramate on the prevention of refractory migraine headache attacks. Armaghan-e-Danesh. 2009;1(14). [in Persian]

17. Martic-Biocina S, Zivoder I, Kozina G. Biofeedback and neurofeedback application in the treatment of migraine. Psychiatr Danub. 2017;29(Suppl 3):575-577.

18. Graef JE, Rief W, Korn HJ, Timmer B, Martin A, Nestoriuc Y. Pilot Study of the Feasibility of a Short Biofeedback Treatment of Chronic Headache in the Outpatient Care System. Psychother Psychosom Med Psychol. 2017;67(1):26-37. [DOI:10.1055/s-0042112462]

\section{How to Cite This Article:}

\section{Download citation:}

$\underline{\text { BibTeX }}|\underline{\text { RIS }}| \underline{\text { EndNote }}|\underline{\text { Medlars }}| \underline{\text { ProCite }} \mid \underline{\text { Reference Manager } \mid \underline{\text { RefWorks }}}$

\section{Send citation to:}

(8. Mendeley (2) Zotero : RefWorks RefWorks 